\title{
VERSITA
}

10.2478/v10284-012-0001-3

\section{MINI COOPER: CURRENT MARKETING STRATEGY, DIGITAL MARKETING APPROACH, THE BRAND \& ETHICAL VALUES}

OXANA SRIBNYAK

\section{ABSTRACT}

This paper aims to analyse the MINI's case study to discover which marketing tools have best served to build a world-class iconic car brand. Using knowledge learned over the marketing course, their current marketing strategy will be analysed in detail. The second part will then critically examine the digital marketing approach of the MINI to answer the question of "what are the benefits to MINI from such a broad approach?"

Drawing on the MINI case study, the paper will explore how emotions are used in marketing to build loyalty to the brand. MINI's successful brand performance, and the spirit created by its brand, the values and beliefs of "typical MINI's buyers" will be investigated in detail.

The paper will also highlight the ethical values of the MINI Company and conclude with opinions about why some car companies put so much emphasis on conducting their business in an ethical manner. 


\section{INTRODUCTION}

"The aim of marketing is to know and understand the customer so well the product or service fits him and sells itself." - Peter F. Drucker

Marketing affects everyone, every day, and in all areas of life. It is the key driver for bringing people goods and services they desire, and includes many different industrial activities, including marketing research, product development, organisation of resource distribution, pricing strategies, press and public relations, advertising and personal selling, a long supply chain that ends in "the sale".

Marketing influences more than just retailers and buyers, but even non-buyers, via impacts on the common environment. But to distill it simply, marketing's main objectives can be identified as the following: "To achieve the highest possible consumption rates, to achieve maximum customer perceptions of satisfaction, to provide consumers with the widest selection possible in the most cost efficient manner, and to maximize the quality of lifestyle" (Peter Drucker, 2006).

Many believe the highest ideal must be to improve the quality of life, but as world famous management consultant Peter Drucker noted, the primary aim of marketing is to better understand customers in order to sell them more products. That is why marketers, the actual people funding the marketing industry, measure the success of campaigns in terms of units moved, not lives improved: 'MINI's introduction into the worldwide market ended in 2002 with more that 144,000 cars sold, which went beyond the expectations of BMW Group and continues significantly to our success"(Bayerische Motoren Werke AG, 2003).

What drives the sales of so many MINIs? Is it so well made that success comes easily? Or is it something more that they sell to consumers, for example the spirit or lifestyle?

These and other questions will now be explored on the next page of this paper.

\section{ANALYSIS OF MINI'S CURRENT MARKETING STRATEGY}

After WWII, Europe saw the immediate rise of demand for affordable cars for the general public, and advances in wartime production brought new processes of production to the consumer production lines.

Across resource-poor Europe, compact car production sprang up, and in the British market, the MINI was born. The project, under the guiding influence of Anglo-Greco car designer Sir Alec Issagonis, launched in 1959 as the UK's first fuel-efficient car. Highly customisable without losing its unique character, (a unique selling point throughout the life of the brand), after two years zooming around British streets, the MINI launched a sportier racing version developed by legendary track-racer John Cooper, the "MINI Cooper", cementing their popularity with the public. Thus this British everyman's car became known as the masculine, small utility car with maximum interior space, a fun road adventure on wheels; a driving experience which to this day influences the brand's marketing positioning.

MINI thrived as an icon around the world for "Cool Britannia", through the Beatles wave in the 60s, spy movies of the 70s, road trip movies of the 80s, to British comedies of the 90s. Then, in 2002, an effort began to revitalise the brand, bringing back the retro image of the MINI, modernising it and targeting it to those most likely to share the same brand values of the company. 
Successful marketing requires vision and resources to develop successful strategies, and while most do not know that the initial designer of the MINI was related to then BMW Director Bernd Pischetsrieder, few today know that today's MINI is a brand owned by the BMW Group, which successfully brought their legendary branding philosophies and resources into effect to develop an integrated marketing strategy that has seen the brand exceed all market expectations (Motor Trader, 2012).

\subsection{MARKETING SEGMENTATION}

Marketing segmentation breaks down the general market into distinct groups, aka "target markets", each requiring different products and influenced by different marketing approaches (Jobber, 2007).

For cost effectiveness, businesses divide markets into manageable segments defined by socioeconomic and cultural factors to better understand consumer demand. MINI has developed their cars to be highly attractive to their target market, and yet still spends tens of millions of dollars each year to ensure effectively reaching those "right" buyers. This is because smart marketers like MINI know that focusing on the right segment is essential for sales, so they use strategic market segmentation to increase profitability. By pricing their cars in the MSRP range of $\$ 19,500$ to $\$ 35,000$, they use the classical models of price discrimination to maximise profitability.

With no "master"method of segmentation, ensuring the target is profitable enough requires experimenting with differing pricing options, further segmenting the market to find the "sweet spot" pricing approaches that increase sales without reducing profitability. MINI, with a 360 degree marketing approach, uses a full arsenal of tools in segmenting consumer markets along geographic, demographic, psychographic and behavioral lines (Jobber, 2007).

Segmentation by geography. By breaking down markets into geographical units: state, regions, counties, cities, even neighborhoods, MINI has the option to act locally, across a region, or even globally, tailoring their branding message to meet the differences in needs and preferences as defined by geography.

Segmentation by demographic lines. Using digital and direct mail to collect data on those most likely to buy, MINI has been very effective in breaking down target markets into groupings based on statistical variables such as gender, age, family size, family life-cycle stage, income levels, occupation, education, religion, race, and nationality. This method is most popular in defining consumers because determining needs and preferences, even consumption frequency, is most often closely associated with demographic characteristics.

Psychographic segmentation. This is where MINI's marketing advantage comes into play, as parent company BWM has long divided buyers into groups based upon social class, upbringing, lifestyle, and likely personality characteristics in order to sell them higher-priced models over their lifetimes. "Niche marketing" is a more expensive customer acquisition method, but offers the best ROI for high-ticket items like automobiles.

Segmentation of behavioural principles. Also known as "consumer behavior", is based on the behavioural characteristics of all buyers, and drives MINI's global marketing strategy. Dividing groups according to patterns of usage and measured reactions to the products, in terms of costs, is the most affordable basis for forming mass-marketing strategies.

MINI claims that they do not identify their customers as a single specific demographic, but since the 2002 re-branding they have chosen to market in each country with differing advertising agencies, which means de facto segmentation (Simm and Trott, 2006). According to AdAge Magazine, January 2012, they have called for an agency review, meaning their current year advertising will be in a holding pattern as they focus all of their resources on finding the right agency to bring all their marketing "under one roof". 
MINI's global marketing strategy to date, dealing with so many fragmented global markets, keeps in mind that "very few cars reach out to so many consumers from such diverse walks of life" (MINI Marketing, 2012). But that same fragmentation makes it necessary to use localised approaches to aggressively grow the market share in markets where some segments do not exist; not every market has developed to the same level of product awareness and familiarity.

At the core of MINI's global strategy is segmentation by demographics. The first are young "affluents", in the 20-34-age range: "Novelty seekers", adventurous and active, they want to stand out and their car helps them do so. They are fashion-oriented, and want a car that reflects their style. The MINI brand matches their attitude and is edgy, fun, and exciting (The MINI Story, 2012).

Slightly older, the second group spans the 35-50 segment, affluent with a progressive worldview. More practical and experienced in life, cars like the MINI are likely to be an additional car, something for their teen children or significant others.

The third group is MINI enthusiasts who love the brand passionately, typically a result of fond memories from youth. This segment makes MINI a "legacy brand", with 9 out of 10 Brits having at one point enjoyed riding in one, so it is only natural that BMW ensured that the styling of the new car evokes those memories in a way to drives sales and strengthen brand loyalty.

\subsection{TARGET MARKETING}

MINI focuses its global strategy on these core targets, researching constantly in order to best profitably engage them via marketing strategies such as: mass marketing (or undifferentiated marketing), differentiated marketing, niche marketing (or concentrated marketing) and micro marketing.

Mass marketing, aka "branding", allows MINI to ignore differences in market segmentation by selling to the greatest number of customers using standardised "global" marketing programmes. MINI can use this strategy because their products are famous worldwide, and the pool of potential buyers is large.

Differentiated marketing allows MINI to approach several market segments simultaneously, each with a unique approach. Cheaper versions might be sold where GDP is lower, larger models targeted to rural audiences, etc. These marcom activities, using insights on the specifics of particular markets, provide better results, but can be costlier, so constantly measuring effectiveness for these promotions is essential.

Concentrated marketing (target) allows better focus on large portions of one or more submarkets and involves "cherry picking"the most promising audiences to market to. Instead of the "shotgun approach"across many markets, MINI focuses on increasing sales where there is more chance of a sale. In market after market, once MINI is established, they then switch focus to other potential growth markets. Considering the demands, the amount spent determines the amount of advertising localisation, and often price reductions and special sales at the dealer level comprise the whole of the marketing effort in some markets (MINI, 2012).

To help dealerships, micro-marketing is used; a strategy where ad-spend is focused on niche groups of desirable consumers. Micromarketing requires defining an audience by things like residential areas or career ranks, and tailoring limited campaigns to that particular segment. Involving significantly more cost due to customisation and tracking, with many executions done repeatedly, so digital and direct mail are the main avenues of this approach. 
A look at MINI's advertising shows that the primary focus is on the younger consumer, both "affluent" and those aspiring to be. When it comes to differentiating these two, the approach is identical, with the aspiring affluent consumer sometimes even more motivated to invest in a product that reflects their selfperceptions, even if that means decreasing spending in other areas. Compare this with luxury brand BMW, targeting professional-class car buyers, especially singles or those with child-raising years behind them, a segment usually with more disposable income (Simm and Trott, 2006).

MINI especially appeals to the fun seekers, even though MINI describes their ideal as being someone just taking off in their career, younger and ambitious, and image conscious. Owning a MINI helps them showcase their success, reflecting their personal style and cosmopolitan worldview. So whether young or old, MINI keeps this at the forefront of the consumer's perception in all its mass-marketing approaches.

\subsection{MARKETING POSITIONING}

Marketing Positioning is the process by which marketers define the product in the public's mind, distinct in relation to other competing products (E. Rice and J. Trout, 1972). This works on the presumption that given too many choices, consumers are generally unable to "desire" the next new product or service. In order for consumers to imagine the benefits of new products, space in the mind ("mindshare") must be released, by closing off knowledge of similar offerings.

MINI's success is a result of positioning their brand in alignment with the legacy of the brand as defined by the public's perceptions, differentiating the brand as unique from competitive offerings, dominating their niche, separate from and different to the competition. Elevating mindshare helps potential customers identify the product with a personality, with the ultimate goal of elevating it to a preference, or "affinity". So if MINI were a person, you would say they are "sneaky, clever, fun, daring, cheeky, even trouble makers".

MINI positions itself as sporty $e r$ fun, and at the same time as fashionable $e r$ trendy. Since 1960, across all media, MINI was positioned as the spunky, masculine, compact motorsport champion. Mass Media showing iconic celebrity MINI owners exemplified the lifestyle, a strategy revitalised via strategic film placement in the 2003 remake of The Italian Job, when they positioned the MINI as a car fast enough to quickly escape quickly the scene of a bank heist. This was not just a chance role, but part of a long term branding strategy: "... film placements are an attractive way to target specific audiences, such as teenagers, and they allow firms to expose their products to consumers who would not normally pay attention to the brand..." (Reibstein, Day and Wind, 2009).

\subsection{MARKETING DIFFERENTIATION}

Differentiation serves to make products unique, focusing on its USP (Unique Selling Points) to make it "stand out" and "outshine"the competition. With increasing awareness over the price of petrol and the polluting of the environment, demand for fuel-efficient compact cars has steadily grown. While "cheaper and weaker" cars have filled that demand for many years, MINI's quality and perceived masculinity helped them dominate the segment as the premium compact car.

But competition grows as demand grows, and the field now includes the VW Beetle, the VW Golf GTI, Alfa Romeo Mito, Fiat's 500, the BMW 1-Series, Audi's A3, and Mazda's Miata series (Simm and Trott, 2006).

Rivaling MINI's niche most strongly is WW's Polo, the Smart Car, and the BMW1. Peugeot's 207 and the VW Polo have taken the most market share from the MINI, but they lack MINI's lifestyle cache, and their purchase motivators lean more towards the practical (Simm and Trott, 2006). For lifestyle motivators, MINI's main competition comes from the Beetle and the Smart Car, which appeal to the same consumer, but have just a fraction of the market share of the MINI. 
Moving forward, MINI's new Countryman is a "Crossover", (a SUV with passenger vehicle features). Functionality is the key USP for this category, and Countryman brings to the table 50 years of MINI legacy and the promise of high performance fun. This is how MINI Countryman stands out from others: "There are cars you use to go to special places. There are cars that are so special, only special people can have them. Then there are cars that turn a simple chore, such as sitting in your car to drive, into a special experience"(MINI Education, 2012).

Expanding a unique personality and lifestyle perception for this new brand will dominate the marketing efforts once a new global advertising agency is selected in 2012. Thus, the main tools of differentiation - promotional advertising and branding - are brought to the forefront, as this researcher will now go into in more detail.

\section{THE DIGITAL MARKETING APPROACH}

Advertising and promoting products via the growing number of digital channels is called "Digital Marketing" a data-driven approach measured in real time, making it a highly-strategic method, rapidly rivaling traditional channels. According to McMains (2012), MINI has narrowed their search as of May 2012 to four advertising agencies, but excluded from this search was the digital work, which is staying with Beam Interactive, whose success can be seen by their effective leveraging of the "above the line" campaigns into online advertising focusing on the core branding platforms of prestige and motion.

MINI's online campaigns mesh perfectly with the print er TV campaigns, the captivating cinema ads, and outdoor "experiential" advertising, except in one notable incident in February 2012, when their German digital agency Sassenbach came up with what seemed a great idea to build awareness of the "wind and weather proof" aspects of the MINI. The digitally-driven exercise involved paying a sponsorship fee to name the cold front "Cooper" after the Mini Cooper, and then encouraging consumers to follow the storm's path on meteorological websites, unaware at the time that the cold front would result in hundreds of deaths. MINI may win many awards for their advertising efforts, but sometimes their attention grabbing digital campaigns necessitate an official apology instead (BBC News Europe, 2012).

Such is the importance of digital as a marketing channel, and MINI has successfully used digital marketing in many new and exciting ways, like MINI France's Google Maps Racing Advergame and NickleFish's 50th Anniversary mobile app game.

MINI's global agency oversees production of display banners matching the current ATL campaigns, all directing consumers to "microsites" built around the brand. MINI's home site serves a very important role as it "funnels" fans towards their own MINI purchase. Much has been spent to ensure a well-designed interface reflective of the wider brand image, with engagement features like the "Design your own MINI" tool, or the interactive "MINI story" which allows users to "Bring a bit of MINI into their life" with free games, screensavers and stylish wallpapers (MINI Education, 2012).

Another channel for localised internet marketing are dealers' websites, and MINI's guidelines ensures that dealer sites match the parent site consistently in tone and look, a difficult task when so many different national agencies are used, each responding to different multicultural marketing consultancies' insights, but overall, brand discipline is maintained across markets by internal audits by MINI's brand managers, who are ultimately responsible for ensuring compliance with global standards. 
Once visitors have made contact, direct mail campaigns come into effect, like the one in 2006 tempting buyers with exclusive offers and an invitation to that year's Motor Show. DM is only as effective as the mailing list, and MINI constantly measures consumer response rates and ensures details are current. Recently, they mailed customers requesting confirmation of their personal contact details, offering them free "handwriting analysis" via handwriting competition entry forms, the winner getting a personalised adventure weekend (MINI Education, 2006).

All these engagement strategies, executed in an across-the-board manner, serve one function: to drive the highest sales results for MINI at the lowest cost. Each discipline works in unity towards that goal, from branding and environmental advertising to raise awareness, to digital campaigns to collect potential consumer data for deeper personal selling efforts. Digital is just a small fraction of the overall marketing budget, but when used correctly can have outsized results during the most crucial phase of the integrated marketing effort, to collect leads for potential buyers. MINI's award winning digital efforts have given them a competitive advantage in this aspect, and will continue to play an important role in future initiatives.

\section{THE SPIRIT OF MINI, EMOTIONS, AND THE BRAND}

\subsection{MOTIVATIONS AND EMOTIONS}

The core strategy is to position MINI with a singular focus: as a great fun-to-drive car, affordable yet upscale, and to channel customers through their life stages into becoming, eventually, lifetime BMW consumers (MINI, 2012).

Consumer motivation is the driving force behind that effort and advertising directs this behavior. Personality is reflected by the general reactions a person exhibits in response to an ongoing situation, based upon emotions, the strong, relatively uncontrolled feelings that affect our behavior (Kapferer, 2004).

These factors are intertwined and difficult to separate. For example, a self-confident consumer (personal characteristic) needs self-affirmation (motivation) so they seek situations that allow them to feel powerful (an emotional response). Self perception is the strongest factor in motivation, personality, and emotions.

Motivation is an invisible, implicit inner strength, enabling behavioural responses, providing specific direction for reactions. Not readily visible, their existence can be determined based upon a customer's purchasing decisions (Kapferer, 2004).

Personality, being the sum of our emotions, is very strong, making it possible to effectively "push"someone to consume. The vividness of such a collection of emotions, so important to the individual, causes companies to tie their brand experience to a recognisable personality as well, to build a consumer "relationship"(Kapferer, 2004).

Emotions in general are controversial. Creative advertising leaves you feeling that you are "in love with the product". It is an experience of brightly colored emotions. But can companies really make someone fall in love with their brand? As the term Lovemarks by Kevin Roberts, CEO of the advertising agency Saatchi e Saatchi shows, in the "post-brand" world, the answer is very much "yes". Someone might buy Product A based upon price considerations, but will spend more for Product B for emotional reasons, even though each product is of similar quality and cost of manufacture. This is why many manufactures spend more on marketing than they do on making their products. 


\subsection{BRAND AND EMOTIONS}

Marketing, done correctly, links the brand with consumer's emotions, but how best to do this? Sometimes it is as simple as showing a model representative of the target group expressing how the brand meets their personal needs. Sometimes "social proof" is required, a demonstration in the context of the peer group. But regardless how, the goal is clear; to make the brand and personal value synonymous. Is this mind control? Very much so, but all is fair in love and business (Kapferer, 2004).

An intensely competitive marketplace pushes companies to take advantage of all technologies of influence, and linking brands emotionally is the only one effective over the long term. Simple familiarisation with the MINI brand shows how everyone can feel the strength of the connection between the brand and its emotional profile.

This is because people buy more than just a car when they buy a MINI. They are buying a spirit, a set of values reflecting the beliefs they express to the world about who they are (MINI Education, 2012). This is seen in MINI's strategic vision: "Match the emotional power of the original mythic model with the technology of the future."

Another branding "strategic vision" is: "To allow people to drive in safety a mythical car while giving it their personal touch, finding everywhere a place to park, and preserving the environment". More than just transportation, drivers seek out the MINI to express themselves. People notice the MINI because its iconic design evokes emotional responses, known as an "emotional modifier"(Simm and Trott, 2006). The same amount of money could be spent on marketing that does not evoke, but to get real value for the marketing effort requires keeping the emotive drives of consumers at the forefront of the marketing effort via analytical understanding of the target consumer, and reaching them with world-class creative executions based on those strategical insights.

\section{THE ETHICAL VALUES OF MINI}

As a proud legacy brand, MINI places a lot of value on relationships, from sales associates, the community, the consumer, to the environment. A strong ethical foundation underlies the parent company's standards for managing the company's social, environmental, and economic footprint. Key to relationships is communication, and communicating their social and ethical standards provides them with many marketing opportunities (Onkvisit and Shaw, 1993).

A look at the parent company's corporate philosophy shows the balance they seek: "n this respect, companies must ensure that their traditional focus on corporate profits and shareholder value is accompanied by equal concern for the needs of society and the environment"(BMW, Corporate Responsibility, 2003).

While one can rightly question if the automobile industry, contributing about $10 \%$ to the world's annual CO2 emissions (Appendix 1), could ever really be considered an "ethical" industry, (given car manufacturer's historical resistance to fuel economy and alternative energy sources, combined with planned obsolescence to ensure frequent car repurchasing), everyone can agree that cars using less fuel is a good start, a belief core to MINI's ethical underpinning. Unlike many car brands, environmental groups generally agree that MINI is doing it right, and to capitalise on the branding aspects of their attention to the "life-cycle assessment"they have created a digital product differentiator that supports the "eco-friendly"brand position.

"Carfun Footprint" (vs. "Carbon Footprint") allows you to measure your existing car's "greenness" against the MINI: "Your Carfun Footprint is a measure of how fun your car is versus how much impact it has on the environment. Determined by using a real equation and real math, it is, in fact, a real number. And the 37-MPG MINI Cooper has the best Carfun Footprint on the road"(MINI, 2012). 


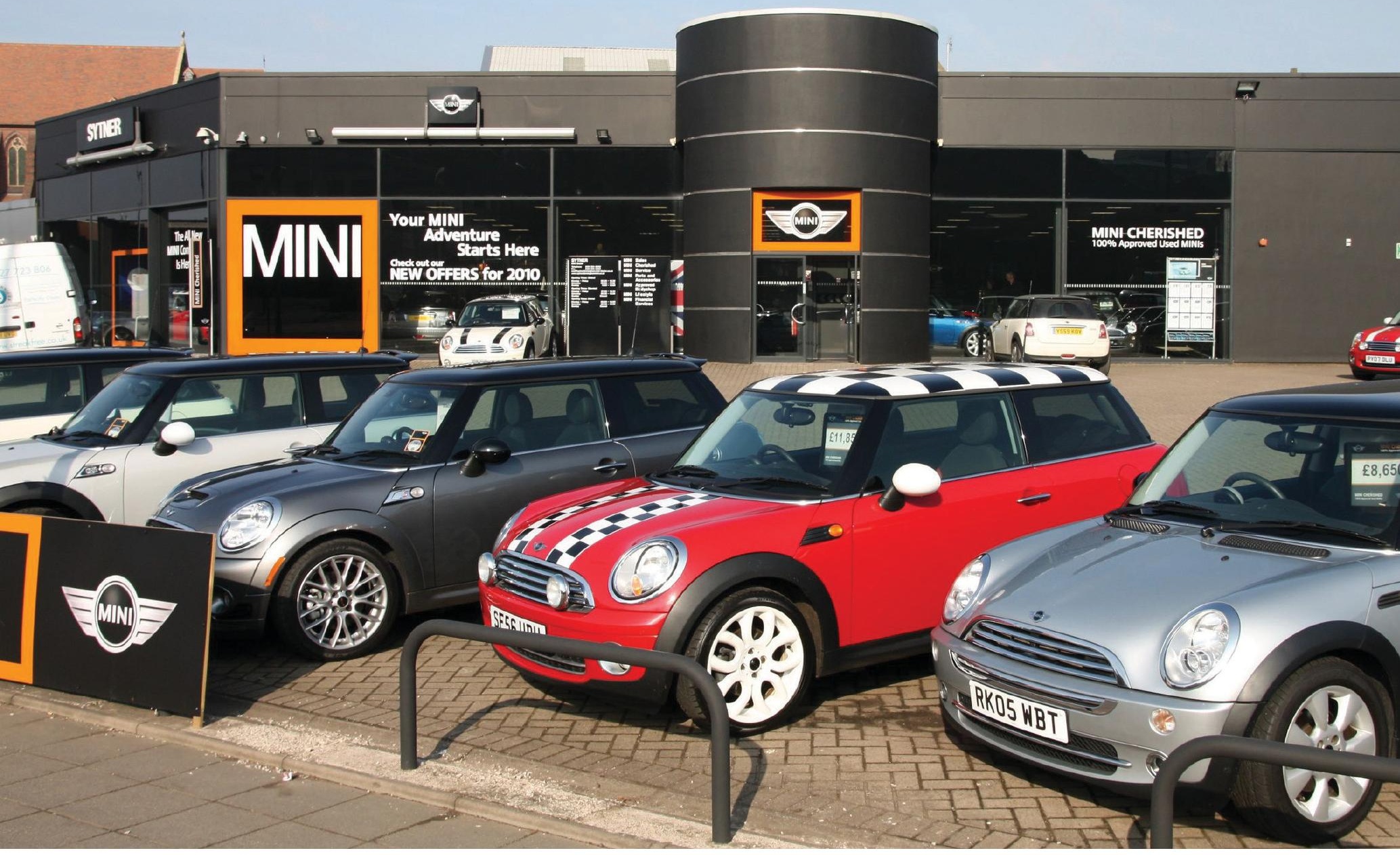

(c) tupungato/123RF.COM

\subsection{SUSTAINABILITY AS A MANAGING PRINCIPLE}

As market leaders, BMW takes seriously concepts of sustainability throughout their operations, based not just on economic considerations, but social and ecological as well. Managing consumer perceptions in light of the long-term environmental damage automobiles cause is a key concern in maintaining profitability as global demand for personal vehicles grows. Their policies are well established; that resources needed by the group are to be used efficiently and sparingly; risk prevention and management is to the highest international standards; and employee actions must enhance the company's reputation in the marketplace. These goals are core to long-term profitability, so one can see why sustainability and business success go together (BMW, 2012).

\subsection{USING RESOURCES RESPONSIBLY}

Handling resources efficiently means responsibly using production materials, water, energy, and capital sustainably, from management to manufacturing, throughout the production chain. In addition to self-audits, each supplier must conduct process audits. And as employees are the storehouse of the brand's future, the BMW Group has developed long-term human-resource development strategies, ensuring employee health and well-being with many proactive programmes and practices (BMW, 2012).

\subsection{RECOGNISING AND MINIMISING RISKS}

As a global company, they face many ecological and social risks that can significantly impact the bottom line, both economically and socially. The public at large regularly shares their concerns with companies to make clear their expectations, and these stakeholder concerns need to be addressed, not just to reduce problems, but also to discover opportunities to engage with the market profitably (BMW, 2012). 


\section{CONCLUSION}

It is well established in the marketplace the critical role marketing plays as one of the most important of human industries, due to its critical role in driving sales throughout the rest of the economy. According to Vranica (2010), the total global advertising spent in 2010 was $\$ 450 B$, making it an almost half a trillion dollar industry.

Any company seeking long-term viability and a profitable return on investments of time, effort, and money will need a well developed and efficient marketing strategy to succeed, and MINI's market dominance shows strong mastery of these principles, via their well-executed and multi-channel marketing strategy. In addition to branding, they defend their market share by building a premium quality car that meets the expectations of their discriminating customers.

By recognising the exponential growth in the premium compact market, MINI has successfully dominated this growing market segment (BMW, 2012). For the parent company, the re-introduction of the MINI is key to BMW's efforts to funnel their customers up the value chain and into the luxury automotive market.

All channels drive future sales growth, from their legacy foundation through to their award winning digital marketing approaches, enabling MINI to cement itself in the mind of the consumer as the fun, stylish car to express yourself in.

There is nothing more emotive than identifying one's self with one's possessions, and MINI has employed strong emotional appeals to connect its brand to that expression of self, in a forward-looking manner that also shows strong stewardship of the environment and society at large. 


\section{REFERENCES}

Blythe, J. (2006) Essentials of marketing communications. 3rd ed. Harlow: FT Prentice Hall Harlow

Jobber, D. (2007) Principles and Practice of Marketing. Maidenhead: McGraw-Hill Education.

Hardey, M. (2012) 'New vision: capturing digital data and market research', International Journal of Market Research, 54(2), pp. 2-9

Gordon, R. (2012) 'Re-thinking and re-tooling the social marketing mix', Australasian Marketing Journal, 20(2), pp. 113-178.

Josiassen, A., Assaf, G. and Karpen, I. (2011) ' Consumer ethnocentrism and willingness to buy: Analyzing the role of three demographic consumer characteristics', International Marketing Review, 28 (6), pp. 627-646.

Drucker, P. (2006) Classic Drucker: The Man Who Invented Management. Boston: Harvard Business School Publishing Corporation.

Kapferer, J. (2004) The new strategic brand management. London: Kogan.

Maklan, S. and Klaus, P. (2011) ' Customer experience: are we measuring the right things', International Journal of Market Research, 53 (6), pp. 23-29.

Onkvisit, S. and Shaw, J. (1993) International Marketing: Analysis and Strategy. New York: Macmillan.

Pickton, D. and Broderick, A. (2005) Integrated marketing communications. 2nd ed. Harlow: FT Prentice Hall.

Riefler, P. (2012) 'Why consumers do (not) like global brands: The role of globalization attitude, GCO and global brand origin', International Journal of Research in Marketing, 29(1), pp. 25-34.

Reibstein, D., Day, G. and Wind, J. (2009) ' The Worth of Product Placement in Successful Films: An Event Study Analysis', Journal of Marketing, 73(4), pp. 45-47.

Simm, C. and Trott, P. (2006) 'The perceptions of the BMW MINI brand: the importance of association and historical model', Journal of Product er Brand Management, 15 (4), pp. 228-238.

Vries., L., Gensler, S. and Leeflang, P. (2012) 'Popularity of Brand Posts on Brand Fan Pages: An Investigation of the Effects of the Effects of Social Media Marketing', Journal of Interactive Marketing, 26 (2), pp. 83-91.

BBC News Europe (2012) 'Mini named lethal weather front 'Cooper' in PR gaffe'. [Online]. Available on: http://www.bbc. co.uk/news/world-europe-16852429 (Accessed: 18 May 2012).

MINI Education (2012) About us. Available at: http:/ www.MINI.co.uk/about-us / (Accessed: 11 April 2012).

McMains (2012) ' 4 Shops Advance in Mini Cooper Review', AdWeek. [Online]. Available on: http://www.adweek.com/ news/advertising-branding/4-shops-advance-mini-cooper-review-138842 (Accessed: 18 May 2012).

The MINI Story (2012) About us. Available at: http://www.MINI.co.uk/about-us/MINI-story/ (Accessed: 15 April 2012). BMW Principle Sustainability (2012) Our philosophy. Available at: http://www.bmw.com/ (Accessed: 21 April 2012).

Car Franchise of the Year Award (2012) Motor trader. Available at: http:/ /www.motortraderawards.com (Accessed: 19 April 2012).

Ministry of Ownership (2012) It knows what your future holds. Available at: http:/ /www.MINIstryofownership.co.uk/ (Accessed: 17 April 2012).

Thrence, A. (2010) Advertising, Promotion, and other aspects of Integrated Marketing. Google Books [Online]. Available at: http://books.google.cz/books?id=wUB9cczGxiACerprintsec=frontcovererdq=Integrated+Advertising, + Promot ion+and+Marketing+Communicationserhl=cserei=E8SeT_zGKsLjtQbo_7iPAQersa=Xeroi=book_resulterct=bookthumbnailerresnum=4erved=0CEEQ6wEwAw\#v=onepagee $q=$ Integrated\%20Advertising\%2C\%20Promotion\%20 and\%20Marketing\%20Communicationserf=false (Accessed on 04 May).

The Italian Job (2003) Directed by Gary Grav [DVD]. USA: Paramount Pictures. http://www.minispace.com/en_us / (2012) (Accessed on 01 May)

Vranica, S. (2010) ' Ad Recovery Picks Up Speed', Journal of Media er Marketing. [Online]. Available at: http://online.wsj. com/article/SB10001424052748704049904575554701849735046.html (Accessed: 18 May 2012). 


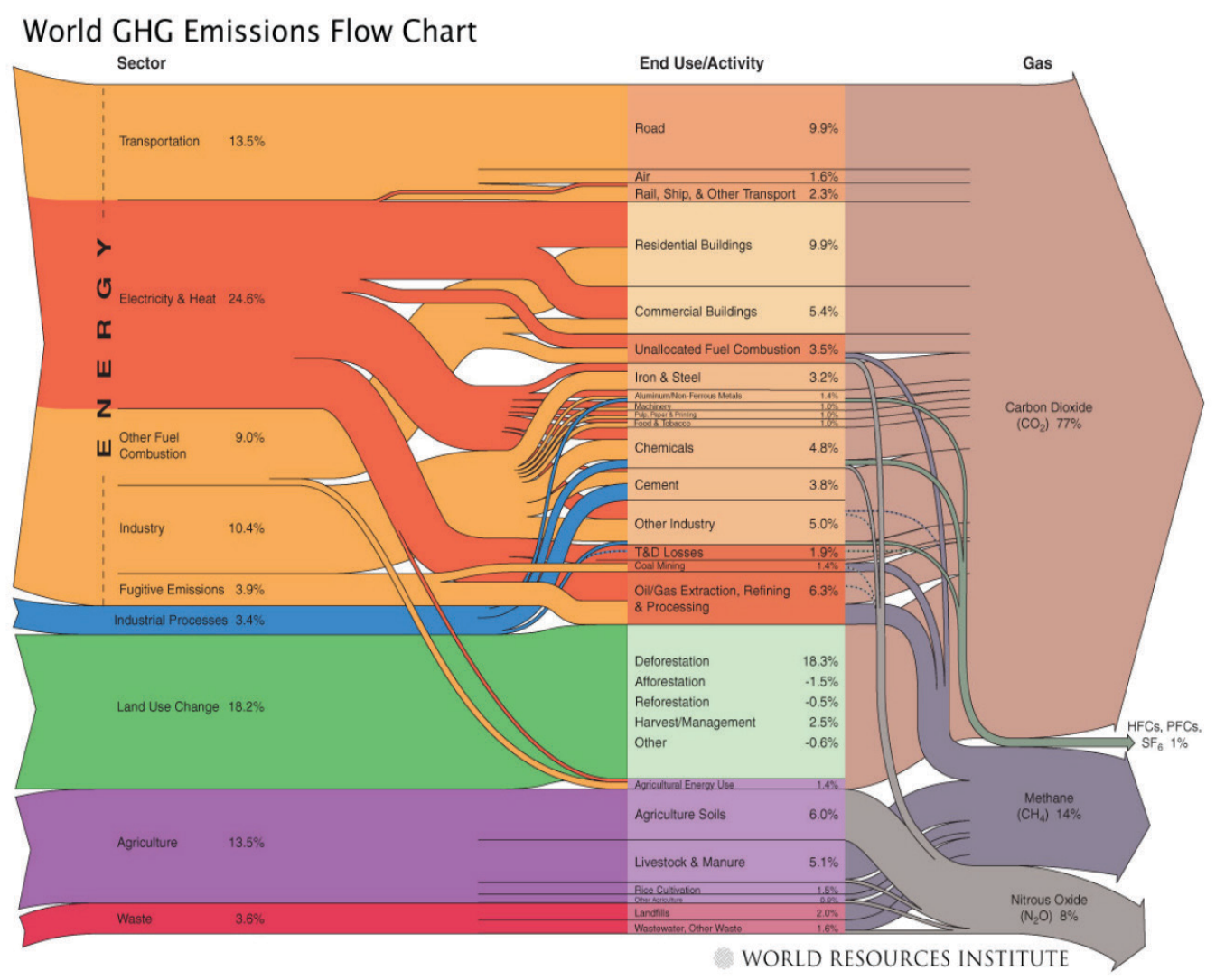

Figure 1: World GHG Emissions Flow Chart, 2012. Source: World Resources Institute. 